\title{
A Dual-Band Multiple Input Multiple Output Frequency Agile Antenna for GPSL1/Wi-Fi/WLAN2400/LTE Applications
}

\author{
Sajid Aqeel, ${ }^{1}$ M. H. Jamaluddin, ${ }^{2}$ Aftab Ahmad Khan, ${ }^{1}$ Rizwan Khan, ${ }^{1}$ \\ M. R. Kamarudin, ${ }^{2}$ Jalil-ur-Rehman Kazim, ${ }^{1}$ and Owais Owais ${ }^{1}$ \\ ${ }^{1}$ Electrical Engineering Department, COMSATS Institute of Information Technology, Abbottabad, Pakistan \\ ${ }^{2}$ Wireless Communication Centre (WCC), Faculty of Electrical Engineering, Universiti Teknologi Malaysia, \\ 81310 Skudai, Johor, Malaysia
}

Correspondence should be addressed to Sajid Aqeel; sajidaqeel@ciit.net.pk

Received 5 August 2016; Revised 3 October 2016; Accepted 23 October 2016

Academic Editor: Toni Björninen

Copyright (C) 2016 Sajid Aqeel et al. This is an open access article distributed under the Creative Commons Attribution License, which permits unrestricted use, distribution, and reproduction in any medium, provided the original work is properly cited.

\begin{abstract}
A novel dual-band, single element multiple input multiple output (MIMO) dielectric resonator antenna (DRA) with a modest frequency tuning ability is presented in this communication. The proposed antenna operates at GPS L1/Bluetooth/WiFi/LTE2500/WLAN2400 frequency bands. A single dielectric resonator element is fed by two coaxial probes to excite the orthogonal modes. A couple of slots are introduced on the ground plane to improve the isolation between antenna ports. The slots also serve the purpose of reconfiguration in the lower band on placement of switches at optimized locations. The measured impedance bandwidth is $5.16 \%(1.41-1.49 \mathrm{GHz})$ in the lower band and $26 \%(2.2-2.85 \mathrm{GHz})$ in the higher band. The lower band reconfigures with an impedance bandwidth of $6.5 \%(1.55-1.65 \mathrm{GHz})$ when PIN diodes are switched ON. The gain, efficiency, correlation coefficient, and diversity gain of the MIMO DRA are presented with a close agreement between simulated and measured results.
\end{abstract}

\section{Introduction}

Wireless communications advancement has necessitated the advent of new standards in order to satisfy the market demands. The Long-Term Evolution (LTE) promises high data rates to cater for ever increasing application demands. LTE frequency bands range from $0.7 \mathrm{GHz}$ to $3 \mathrm{GHz}$ [1] The multiple input multiple output (MIMO) communication systems have received considerable attention to enhance the channel capacity, link reliability, better network coverage, and high data rates for mobile wireless networks [2]. MIMO antennas are deployed to exploit multipath fading in a rich scattering environment. The fundamental requirement for a MIMO antenna is to have low signal correlation and mutual coupling so that multiple signals can be resolved efficiently. A number of MIMO antennas for LTE and wireless fidelity (Wi-Fi) applications have been reported in recent literature [3-5]. Most of them, however, use microstrip antennas whose efficiency is compromised due to conductor losses at high frequencies with high power at base stations.
The dielectric resonator antenna (DRA) is an appropriate choice for wireless communication systems due to their inherent benefits that include high radiation efficiency, no conduction losses, ease of excitation, and more design freedom [6]. Despite the benefits, little work is carried out on dual polarized MIMO DRAs [7-10]. A dual-band cylindrical DRA with orthogonal excitation scheme is presented in [7], whereas a multiband DRA is presented in [8]. However, the isolation at lower band is very poor in [8]. The work in [9] presents a dual polarized cylindrical DRA with good isolation but a relatively large size. A rectangular DRA for WLAN applications is presented in [10].

An antenna structure supporting the GPS band along with the wireless communication bands is much preferred as it circumvents the requirement of a separate antenna [11]. Generally, the GPS antennas are right-handed circularly polarized (RHCP). A GPS-enabled device operates in a typical urban environment, where the presence of trees and buildings may force the signal to become left-handed circularly polarized (LHCP). A linearly polarized GPS antenna is a 
better alternative to the RHCP antenna as it is less susceptible to the environmental distortions [4]. A linearly polarized antenna is able to receive signals from more satellites and thus provides better coverage.

The multiband and reconfigurable antennas have an added advantage to cover a much wider spectrum while retaining the same small size. A few multiband MIMO antennas that provide the GPS band coverage along with the other wireless communication bands [4, 12-15] are reported in recent literature. A quad band MIMO antenna comprising two PIFA elements is presented in [4]. Two conventional monopole antennas which are connected by suspended line to reduce the mutual coupling are presented in [12]. In [13, 14], design of dual feed multiband antenna is proposed. In [15], a MIMO antenna comprising two planar inverted $\mathrm{F}$ antennas and five inverted $\mathrm{F}$ antennas is proposed for GPS and wireless communication bands.

The main contribution of this work is the design of a single element, dual-band MIMO DRA having a modest frequency agility capability that covers the GPS L1 band along with a number of LTE bands. The frequency agility is obtained through PIN diodes placement on the ground plane. Reasonably good isolation is achieved between the antenna ports in both configurations. Perturbation techniques are employed to widen the impedance bandwidth, whereas the slots introduction on ground plane helps enhance isolation along with reconfiguration capabilities. To the best of our knowledge, this is the first single element, dual-band MIMO frequency agile DRA which integrates the GPS and LTE bands.

Section 2 describes the antenna design and geometry. In Section 3, the working principle of design is investigated through a parametric study. Frequency agility by employing tabs on the slots is demonstrated in Section 4. Section 5 provides the experimental results including $S$-parameters, antenna efficiency, and gain, whereas MIMO parameters like correlation coefficient, diversity gain, and mean effective gain are presented in Section 6. Finally, Section 7 concludes the current communication.

\section{Antenna Design and Geometry}

A cross shape DRA of $\varepsilon_{r}=10$ is placed on a $(100 \times 100 \times$ $1.6 \mathrm{~mm}^{3}$ ) FR4 substrate of $\varepsilon_{r}=4.6$. Two coaxial probes excite the structure for a MIMO operation. On the ground plane, two rectangular slots of length $=17 \mathrm{~mm}$ and width $=2 \mathrm{~mm}$ are placed around the feeding probes for isolation enhancement. Two PIN diodes are placed on the slots as shown in Figure 1. The ON-OFF combination of the PIN diodes resonates the structure in two different configurations. Figure 1 also shows the DC slot lines for ground separation, DC bias lines, and a number of capacitors and inductors. A cylindrical air gap of radius $a_{r}=7 \mathrm{~mm}$ and height $=23 \mathrm{~mm}$ is drilled in the center of the DRA and the edges are chamfered for slight tuning of the lower band. The optimized antenna parameters after the parametric study of the design are summarized in Table 1.

Dual-band operation is obtained by exciting a fundamental mode and a higher-order mode. For a MIMO system, the excited modes should have the same resonant frequency and the shared impedance bandwidth. The placement of feeding
TABLE 1: MIMO antenna design parameters.

\begin{tabular}{lc}
\hline Variable & Val. $(\mathrm{mm})$ \\
\hline$L$ & 100 \\
$a$ & 13 \\
$d$ & 9 \\
$W$ & 100 \\
$b$ & 4 \\
$P$ & 19 \\
$h$ & 23 \\
$c$ & 5 \\
$a_{r}$ & 7 \\
\hline
\end{tabular}

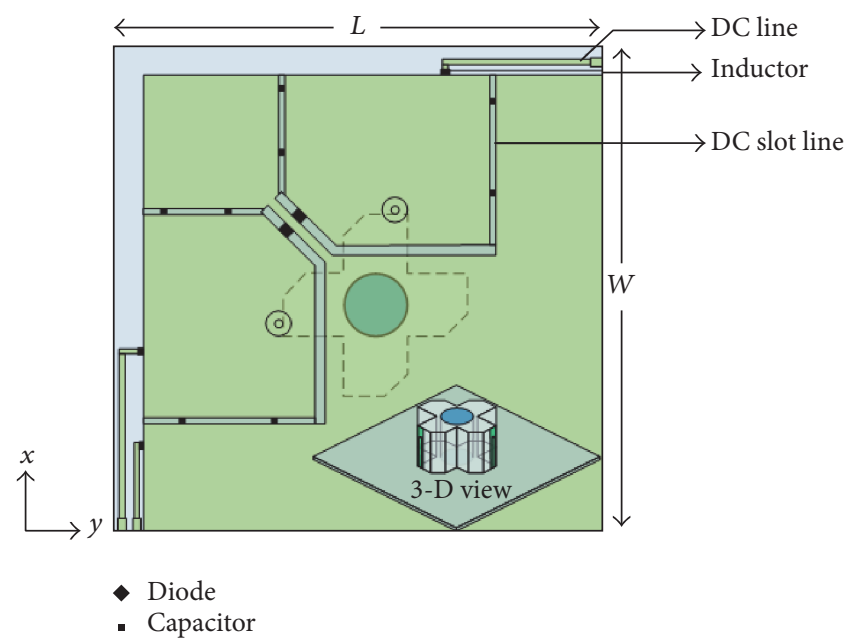

(a)

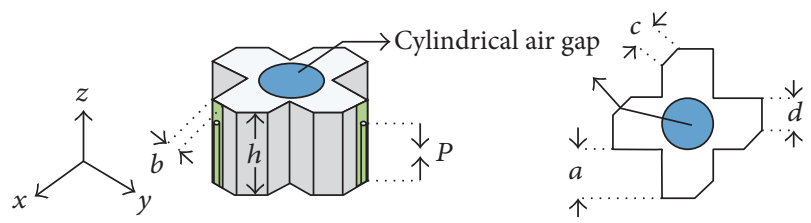

(b)

FIGURE 1: Schematic of the proposed antenna showing bottom, 3D, and top views. The bottom view depicts slots, DC bias lines, diodes, capacitors, and inductors.

ports at optimized locations not only guarantees the same resonant frequencies but also ensures the quasi orthogonality of the respective modes.

\section{Parametric Study}

The initial dimensions of the structure are approximated using the dielectric waveguide model in [16]. The dual-mode resonant frequencies of the rectangular DRA are given as

$$
f_{1,2}=\frac{c}{2 \times \pi \times \sqrt{\varepsilon_{r}}} \sqrt{K_{x 1, x 2}^{2}+K_{y 1, y 2}^{2}+K_{z 1, z 2}^{2}}
$$




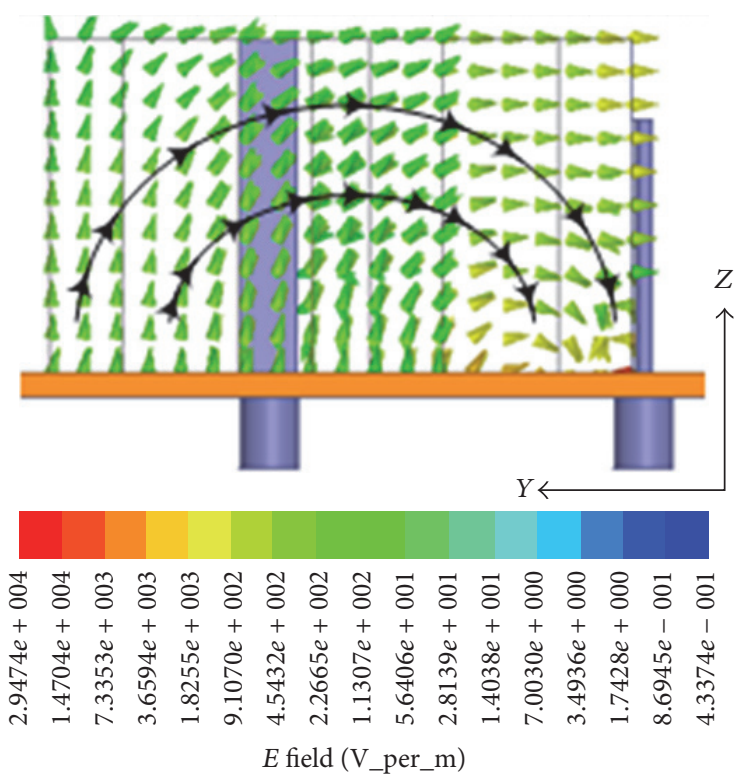

(a)

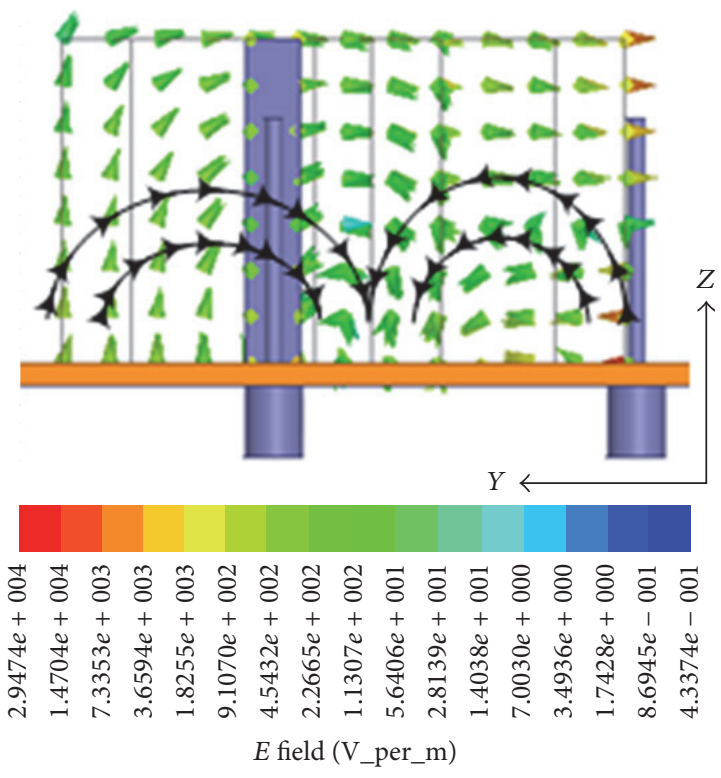

(b)

FIGURE 2: Electric field patterns of port 1: (a) $1.47 \mathrm{GHz}$ and (b) $2.31 \mathrm{GHz}$.

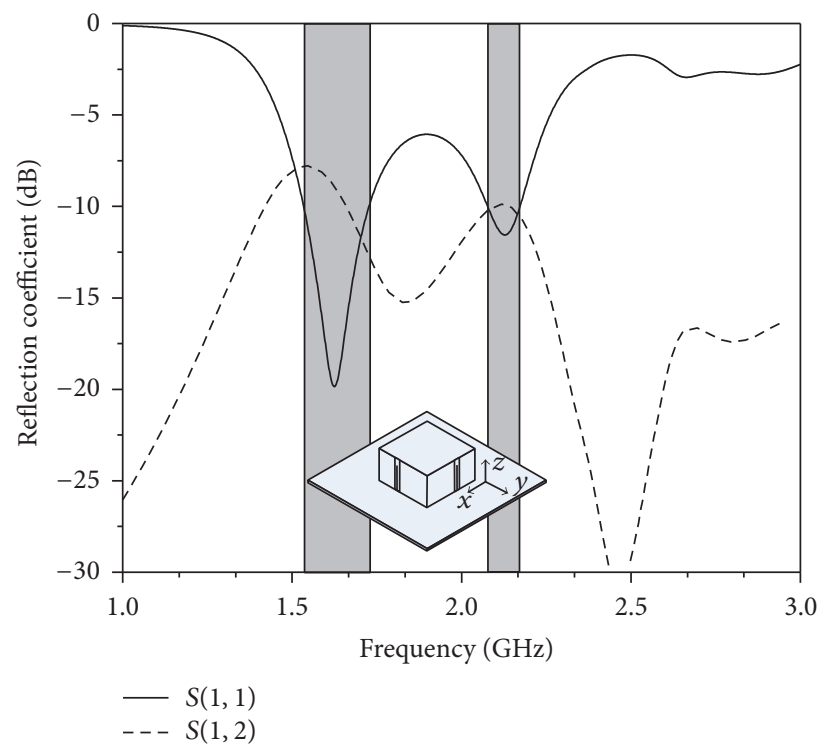

FIGURE 3: Simulated reflection coefficient with dimensions calculated using DWM.

where

$$
K_{z 1, z 2}=\sqrt{K_{1,2}^{2}-K_{x 1, x 2}^{2}+K_{y 1, y 2}^{2}}
$$

where $c$ is the speed of light.

Both ports excite two modes. For lower-order mode, $k_{y 1}=k_{y 2}=\pi / b$, and $k_{x 1}=k_{x 2}=\pi / a$. Similarly, for the higher-order modes, $k_{y 1}=k_{y 2}=2 \pi / b$, and $k_{x 1}=k_{x 2}=$ $2 \pi / a$.

The E-field patterns corresponding to the lower and higher resonance frequencies are shown in Figure 2. It is evident from Figure 2 that the modes excited through port
1 are $\mathrm{TE}_{\delta 11}^{x}$ and $\mathrm{TE}_{\delta 21}^{x}$. The symmetrical feeding port 2 excites $\mathrm{TE}_{1 \delta 1}^{y}$ and $\mathrm{TE}_{2 \delta 1}^{y}$. The excited modes are quasi-orthogonal, which help achieve polarization diversity.

DRA of dimensions $\left(40 \times 40 \times 23 \mathrm{~mm}^{3}\right)$ resonates at 1.6 $\mathrm{GHz}$ and $2.15 \mathrm{GHz}$ but has an inadequate matching and a narrow bandwidth as shown in Figure 3. The isolation at the lower band is high and it needs to be addressed. Moreover, shifting of the higher band is desired to cover the Wi-Fi $2.4 \mathrm{GHz}$ and LTE $2.5 \mathrm{GHz}$ bands. A number of techniques that include the (1) perturbation in DRA shape, (2) insertion of a cylindrical air gap, and (3) placement of slots on the 


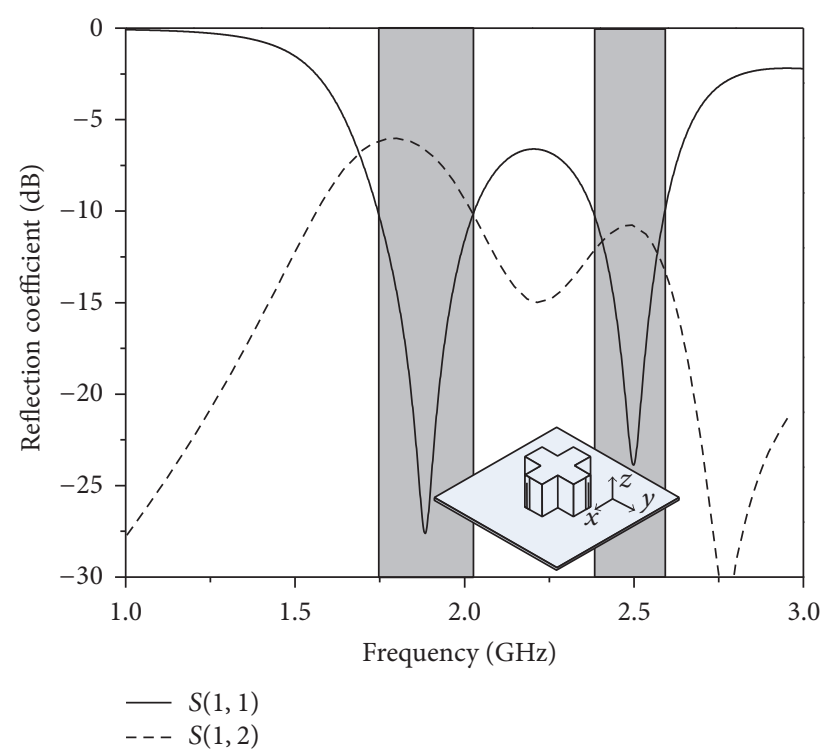

FIGURE 4: Simulated reflection/isolation coefficient with a perturbation in DRA shape.

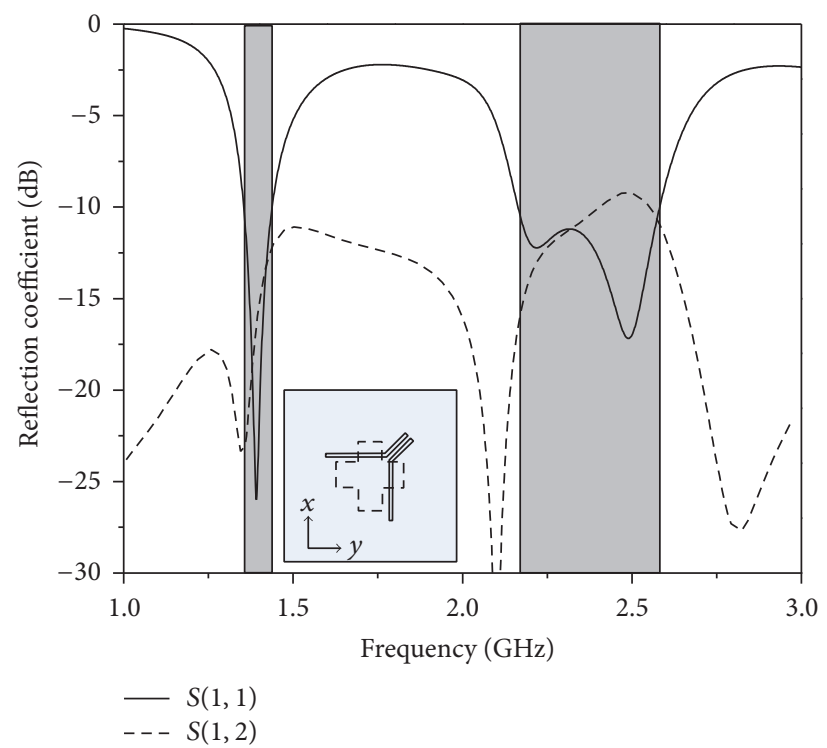

FIGURE 5: Simulated reflection coefficient with slots on the ground plane.

ground plane are used to tune the structure to the desired bands.

The details of the parametric study on these parameters are described in following sections. All the simulated results described here are obtained using HFSS v.15.0 [17]. Due to the symmetry of the design, $S_{11}$ and $S_{22}$ are exactly the same; therefore only $S_{11}$ is shown in Figures 3-6.

3.1. DRA Shape. The resonance frequency can be shifted by introducing a cavity perturbation inside the DRA. A cross shape DRA perturbation is chosen to preserve the design symmetry. Symmetrical notches $(23 \mathrm{~mm} \times 23 \mathrm{~mm})$ carved from the DRA corners result in an enhancement of the impedance bandwidth [18], as shown in Figure 4. The higher band shifts to the required bands after the perturbation; however, the coupling at lower band is high.

3.2. Slot Length. A slot on the ground plane between two antenna elements alters the current path, thereby reducing the mutual coupling [19]. Around each feeding port, a rectangular slot is introduced to enhance the isolation between two ports of the single radiating structure. The parasitic slots placed on the ground plane of the DRA alter the resonance frequency and result in a much wider impedance bandwidth [20], as shown in Figure 5. 


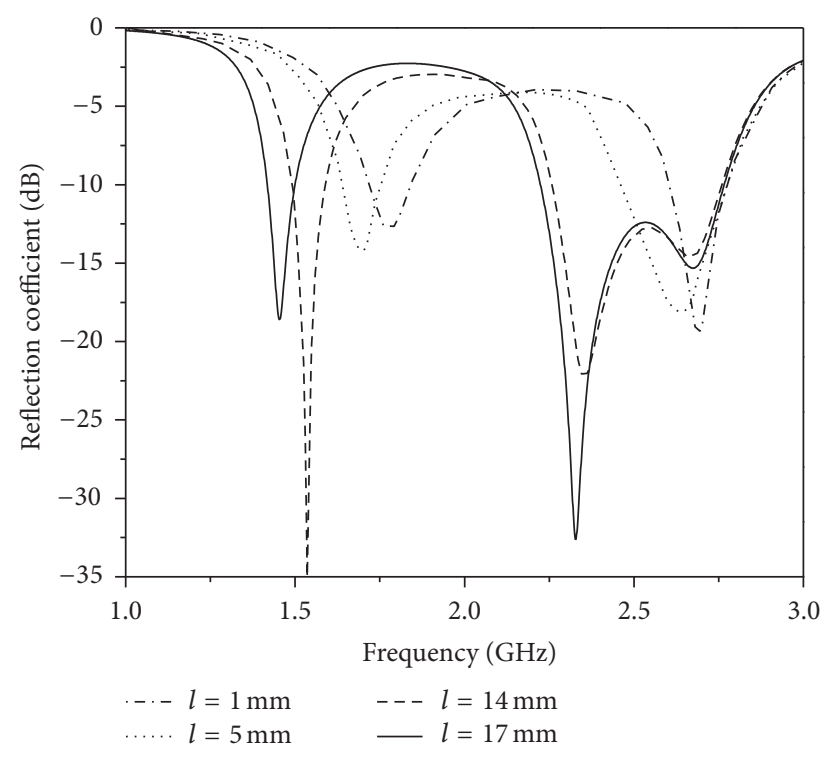

Figure 6: Simulated reflection coefficient for different slot lengths.

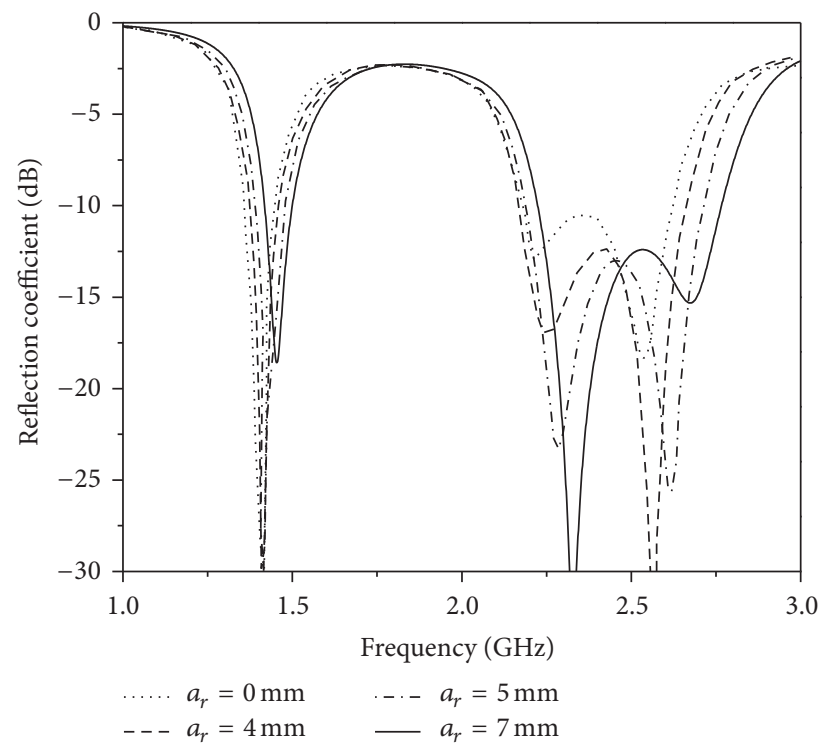

FIgURE 7: Simulated reflection coefficient for different values of the cylindrical air gap radius $a_{r}$.

Figure 6 shows the effect of slot length variation on the simulated $S$-parameters. The resonance frequency decreases with an increase in the slot length. The slot length of $l=$ $17 \mathrm{~mm}$ is selected for final design choice in order to meet the requirements of both bands.

3.3. Cylindrical Air Gap. The variation of the reflection coefficient with the cylindrical air gap radius $\left(a_{r}\right)$ is shown in Figure 7. With an increase in the radius, the resonance frequency also increases as the volume of the DRA becomes smaller. A value of $a_{r}=7 \mathrm{~mm}$ is chosen to ensure the LTE band $X 1$ requirements.

\section{Isolation Enhancement and Frequency Agility}

Figures $8(a)$ and 8 (b) show surface current distributions with slots at $1.47 \mathrm{GHz}$ and $2.4 \mathrm{GHz}$, respectively, whereas Figures $8(\mathrm{c})$ and $8(\mathrm{~d})$ are the current distribution without slots. It is obvious that, without slots, the coupling between two feeding ports is high. The presence of slots on the ground plane prevents the current flow from reaching the other port and lowers the coupling at both bands.

In order to integrate the GPS L1 bands with LTE bands, frequency agility in the lower band is desired. The frequency 

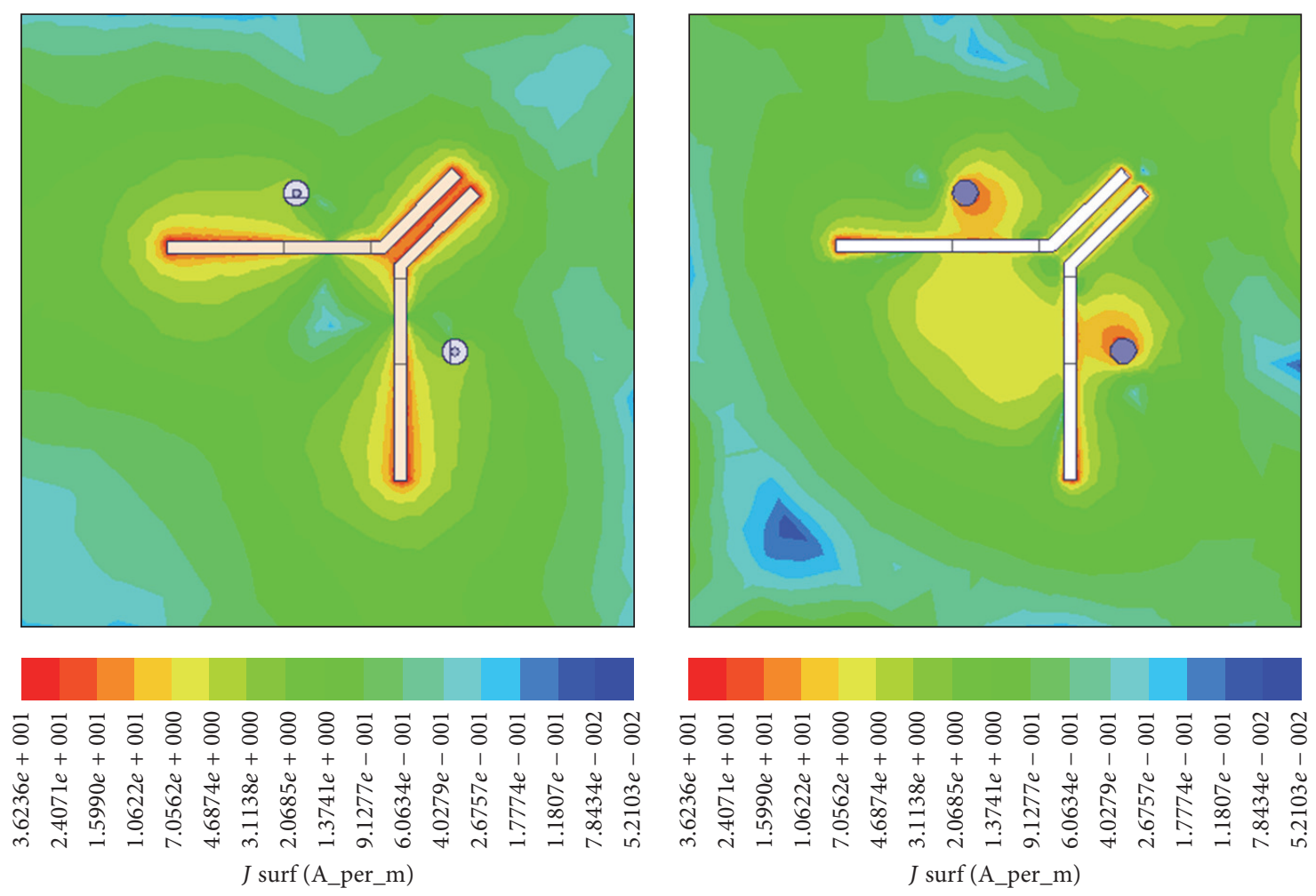

(a)

(b)
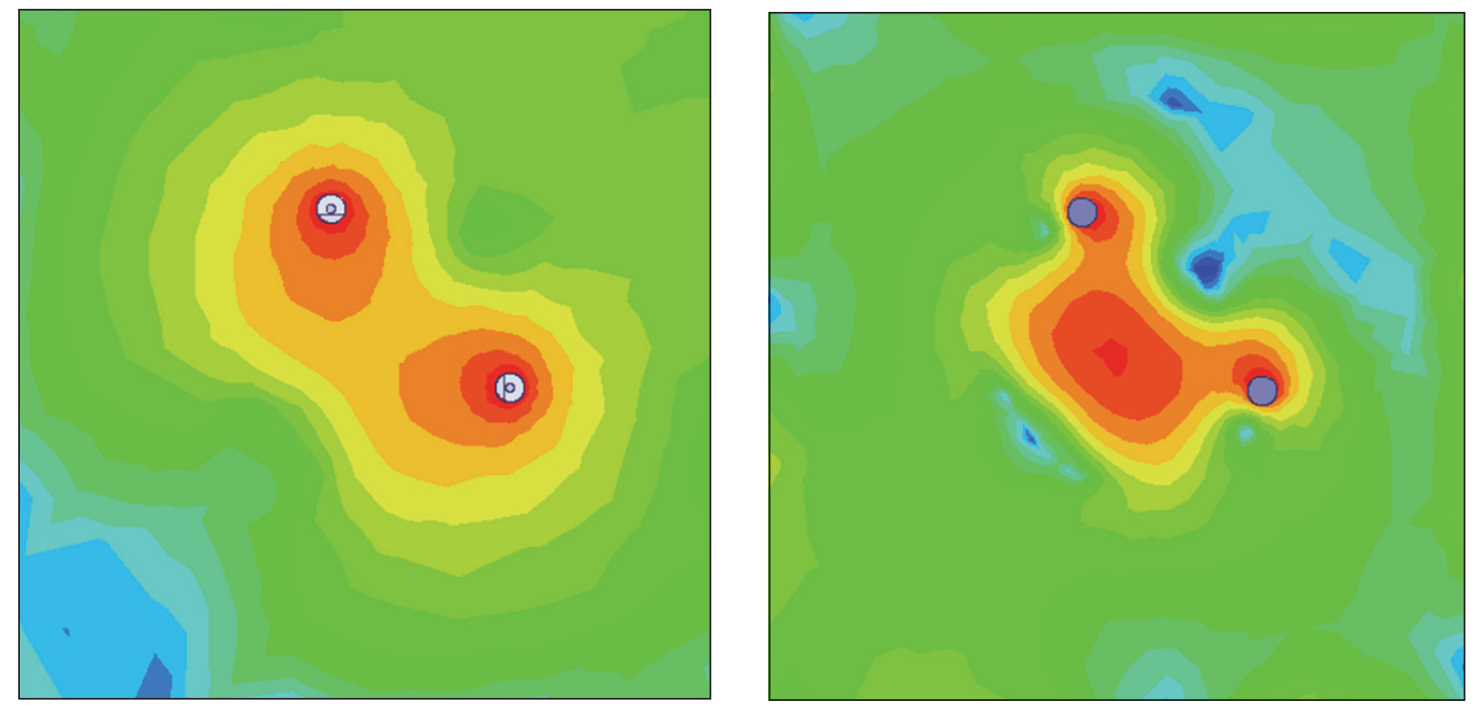

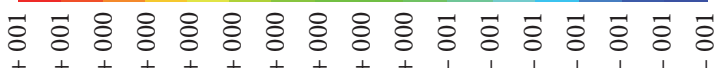

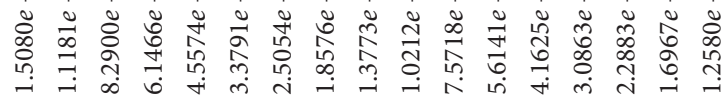
$J$ surf (A_per_m)

(c)

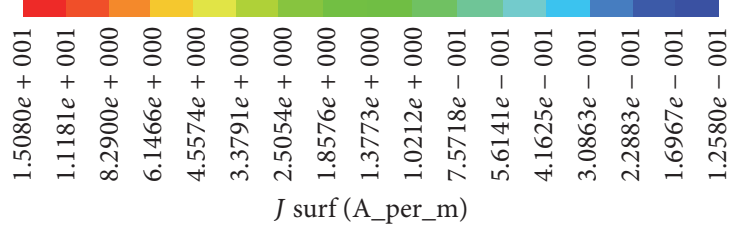

(d)

FIGURE 8: Current distribution plots (a) with slots at $1.47 \mathrm{GHz}$, (b) with slots at $2.4 \mathrm{GHz}$, (c) without slots at $1.47 \mathrm{GHz}$, and (d) without slots at $2.4 \mathrm{GHz}$. 


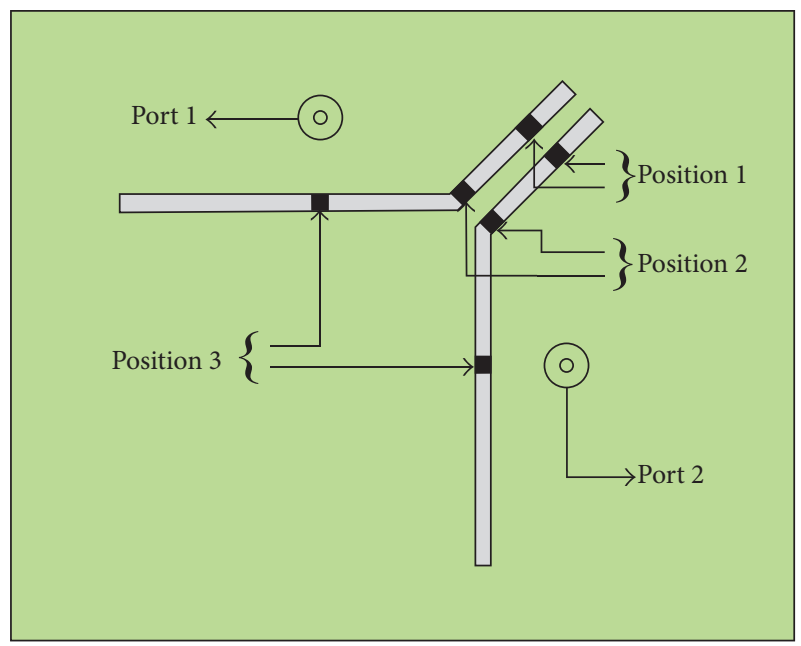

(a)

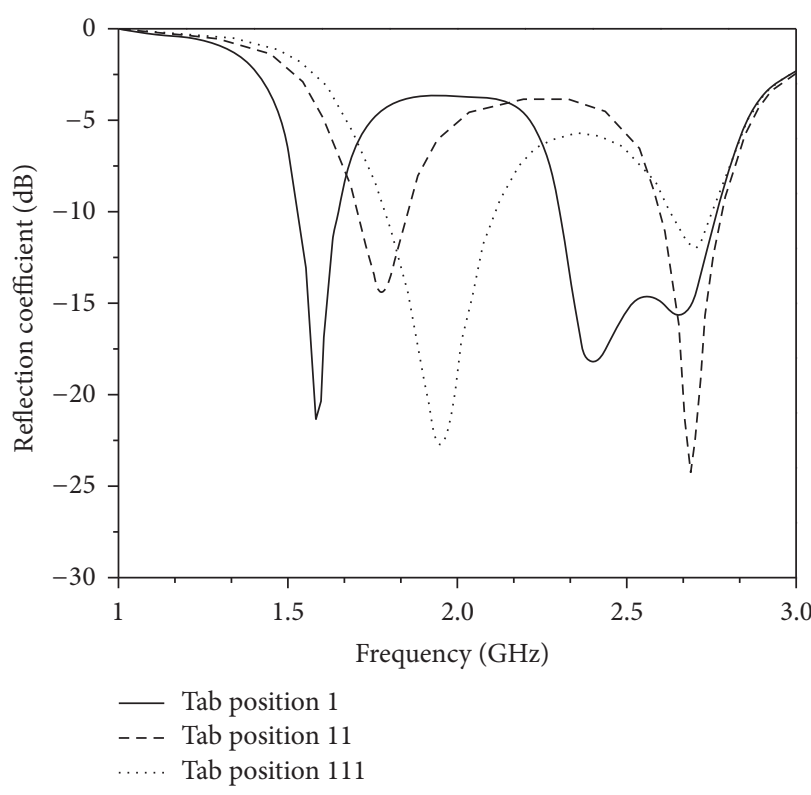

(b)

Figure 9: Simulated reflection coefficient for different tab positions.
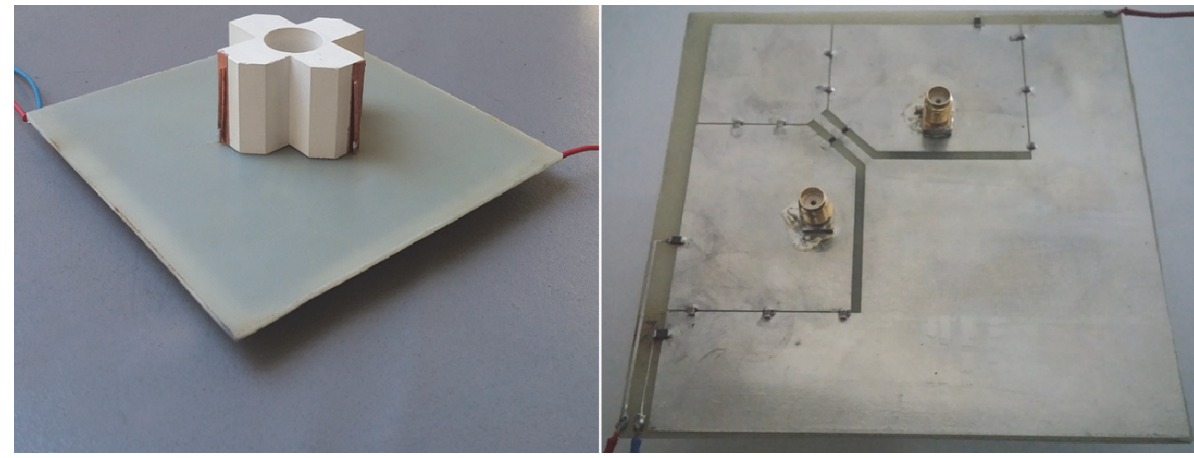

FIgURE 10: Prototype of the fabricated antenna along with the slots on the ground plane.

agility is realized by providing an alternate current path between the portions of the ground planes separated by slots. The new current path is provided by placing ideal tabs (of size $2 \mathrm{~mm} \times 2 \mathrm{~mm}$ ) on the slots. The presence of tabs represents an ideal short circuit between two portions, while the absence represents an ideal open circuit. The presence of tab decreases the effective slot length and causes a shift of resonance frequency. The amount of shift depends upon the location of tab. Three different tab locations and the corresponding reflection coefficient are shown in Figure 9. The required frequency agility in the lower band is achieved by selecting tab position 1 in the final design.

To accurately study the frequency agility characteristics of the proposed antenna, the tabs are replaced by PIN diodes. PIN diodes BAR-64-02V from Infineon Technologies [21] have been used. The diodes exhibit low capacitance $(0.17 \mathrm{pF})$ and resistance $(1.5 \Omega)$ with a forward biased current of $10 \mathrm{~mA}$.
An insertion loss of $0.6 \mathrm{~dB}$ and a high isolation from $1 \mathrm{MHz}$ to $6 \mathrm{GHz}$ make them appropriate choice for the proposed design. The ground plane is detached by $0.3 \mathrm{~mm}$ DC slot lines for the purpose of DC isolation. A number of $100 \mathrm{pF}$ capacitors are placed at the DC slot lines to allow effective RF wave connection. The DC bias lines that turn ON and OFF the two PIN diodes are terminated by $68 \mathrm{nH}$ inductors. The inductors create high impedance and prevent the RF signal from flowing into the bias lines.

\section{Simulation and Experimental Results}

A prototype of the designed antenna is fabricated to validate the simulated results. The fabricated antenna and the ground plane with biasing circuitry are shown in Figure 10. Measurements were carried out using a 4-port Agilent E5071C ENA network analyzer. The measured and simulated reflection 


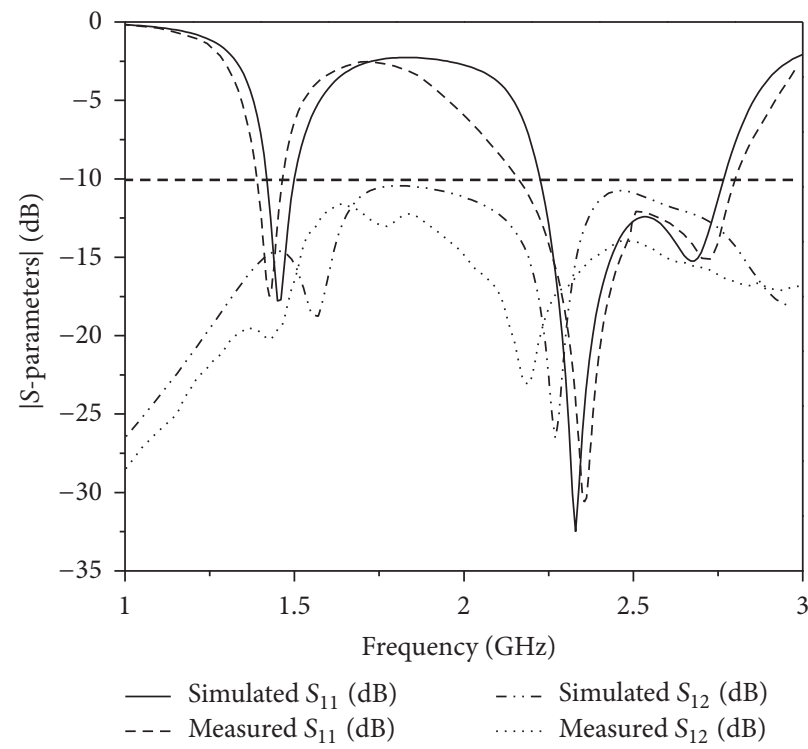

FIgURE 11: The simulated and measured $S$-parameters (dB) for the first configuration (PIN diodes switched OFF).

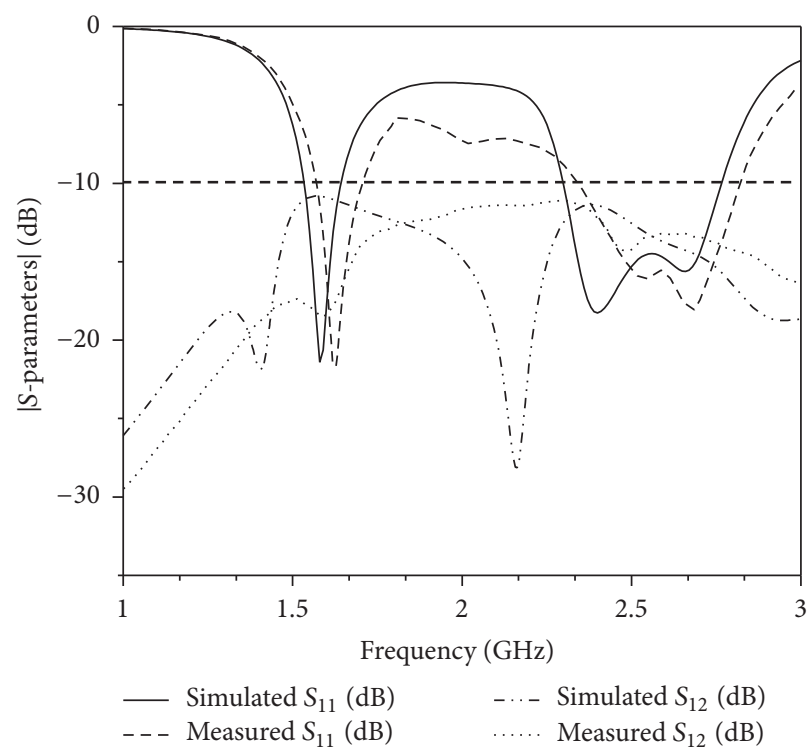

FIGURE 12: The simulated and measured S-parameters (dB) for the second configuration (PIN diodes switched ON).

coefficients for the first (PIN diodes OFF state) and second configurations (PIN diodes ON state) are shown in Figures 11 and 12, respectively. The symmetrical design depicts a similar behavior for port 2 reflection coefficient $S_{22}(\mathrm{~dB})$; however, it is not shown due to brevity.

A close agreement has been found between simulated and measured results. The small discrepancies owe to the tolerances of bias components, the diode package parasitic, and/or the fabrication accuracy of the design.

The simulated and measured port 1 copolarization and cross-polarization radiation patterns for both configurations corresponding to four different frequencies are shown in
Figure 14. The antenna has the maximum radiation pattern in the broadside direction with a good isolation between the copolarization and cross-polarization levels, which ensures an excellent MIMO performance. The port 2 copolarization and cross-polarization radiation patterns show similar behavior; however, they are not shown due to brevity.

The total antenna efficiency $\eta$ for both ports is expressed as

$$
\begin{aligned}
& \eta_{1, \text { total }}=\eta_{1, \text { rad }}\left(1-\left|S_{11}\right|^{2}-\left|S_{12}\right|^{2}\right), \\
& \eta_{2, \text { total }}=\eta_{2, \text { rad }}\left(1-\left|S_{22}\right|^{2}-\left|S_{21}\right|^{2}\right) .
\end{aligned}
$$




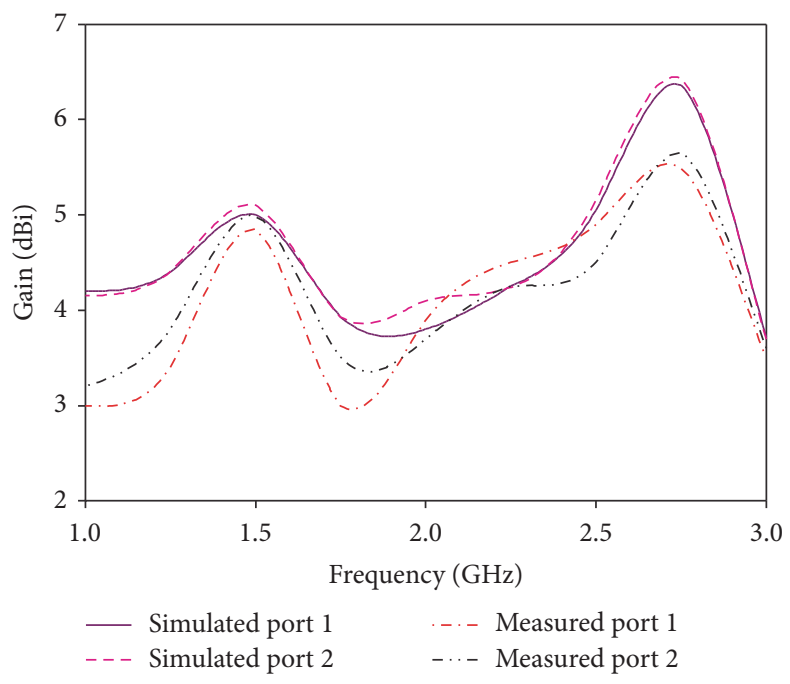

FIGURE 13: Simulated and measured gain for both ports.

TABLE 2: Antenna radiation efficiency and gain.

\begin{tabular}{lccc}
\hline$f(\mathrm{GHz})$ & $\eta_{1} \%$ & $\eta_{2} \%$ & Gain $(\mathrm{dBi})$ \\
\hline 1.47 & 88.9 & 88.6 & 4.83 \\
1.57 & 87.4 & 87.1 & 5.27 \\
2.4 & 91.3 & 91.1 & 4.92 \\
2.5 & 89.4 & 89.7 & 4.70 \\
\hline
\end{tabular}

The total antenna efficiency is summarized in Table 2. The simulated and measured antenna gains are shown in Figure 13.

\section{MIMO Performance Evaluation}

For MIMO performance evaluation, the envelope correlation coefficient (ECC), diversity gain (DG), and the mean effective gain (MEG) are computed. The envelope correlation coefficient (ECC) provides a measure of the antenna spectral efficiency. A low value of ECC is desired for better performance. The ECC can be approximated through the $S$-parameters and the far-field radiation patterns as

$$
\begin{aligned}
& \rho=\frac{\left|S_{11}^{*} S_{12}+S_{21}^{*} S_{22}\right|^{2}}{\left(1-\left(\left|S_{11}\right|^{2}+\left|S_{21}\right|^{2}\right)\right)+\left(1-\left(\left|S_{22}\right|^{2}+\left|S_{12}\right|^{2}\right)\right)}, \\
& \rho=\frac{\left|\iint_{4 \pi} \widetilde{E}_{1}(\theta, \phi) \widetilde{E}_{2}^{*}(\theta, \phi) d \Omega\right|^{2}}{\sqrt{\iint_{4 \pi}\left|\widetilde{E}_{1}(\theta, \phi)\right|^{2} d \Omega \iint_{4 \pi}\left|\widetilde{E}_{2}(\theta, \phi)\right|^{2} d \Omega}},
\end{aligned}
$$

where $\widetilde{E}_{i}(\theta, \phi)=E_{\theta}^{i} \widehat{a_{\theta}}+E_{\phi}^{i} \widehat{a_{\phi}}$ is the radiation field corresponding to the $i$ th port, $E_{\theta}$ and $E_{\phi}$ are radiation field components in $\widehat{a_{\theta}}$ and $\widehat{a_{\phi}}$ directions, and $*$ denotes the complex conjugation [22]. The simulated and measured ECC for the first configuration are shown in Figure 15.
The diversity gain is another important parameter for MIMO antennas. It provides the diversity characteristics and is closely associated with envelope correlation coefficient. The lower the envelope correlation is, the better the diversity gain is. The diversity gain is given as

$$
\mathrm{DG}=10 \sqrt{\left(1-|0.99 \rho|^{2}\right)}
$$

The mean effective gain (MEG) defines the power received at antenna while taking into account the effects of antenna radiation efficiency, radiation power, and the propagation effects [22]. The envelope correlation coefficient, diversity gain, and mean effective gain values at four operating frequencies are summarized in Table 3. From Table 3, it is clear that the proposed antenna satisfies the diversity criteria: ECC $<0.5$ and $\left|\mathrm{MEG}_{1} / \mathrm{MEG}_{2}\right|<3 \mathrm{~dB}[22]$.

\section{Conclusion}

A dual-band MIMO DRA with a reconfigurable lower band is designed and implemented. Two feeding probes excite orthogonal modes in a cross shape DRA to resonate it at 1.47 GHz and $2.4 \mathrm{GHz}$ simultaneously. The isolation between two ports is enhanced by placing slots on the ground plane. By switching the PIN diodes ON, lower band shifts by $100 \mathrm{MHz}$. The antenna covers a number of different LTE bands and GPS/L1 band when operated in one of the two possible configurations. The presented results, envelope correlation coefficient, diversity gain, and the mean effective gain make it suitable choice for MIMO LTE applications.

\section{Competing Interests}

The authors declare that there are no competing interests regarding the publication of this work. 


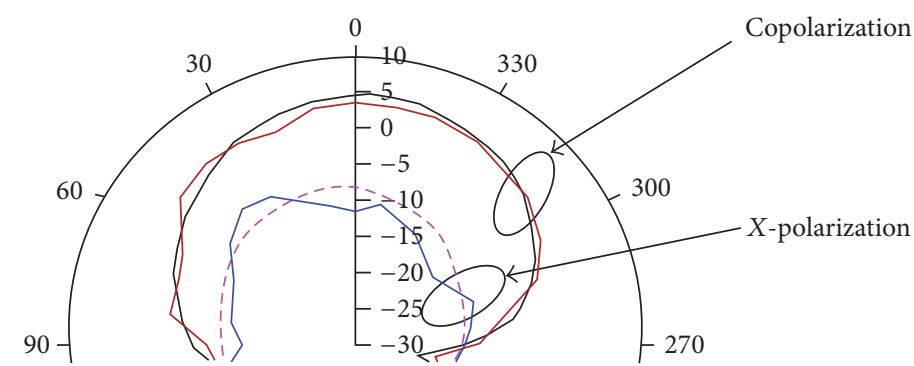

(a) E-plane, $1.47 \mathrm{GHz}$

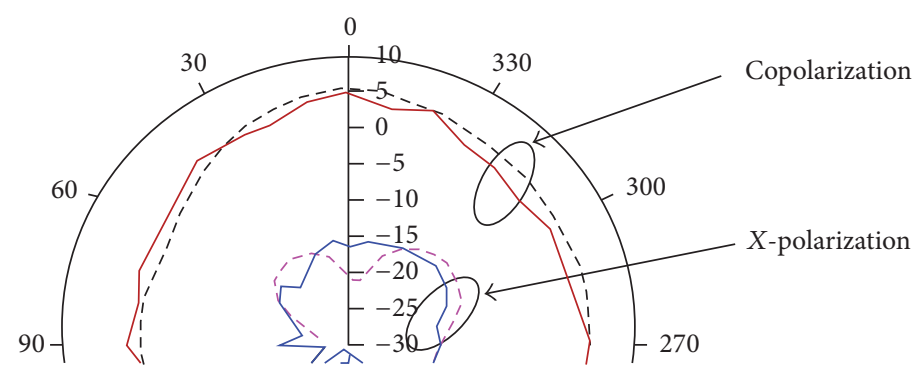

(c) E-plane, $2.4 \mathrm{GHz}$

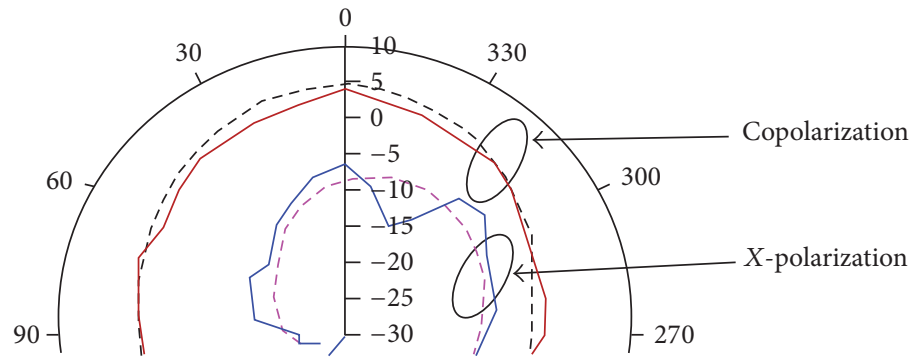

(e) $H$-plane, $1.47 \mathrm{GHz}$

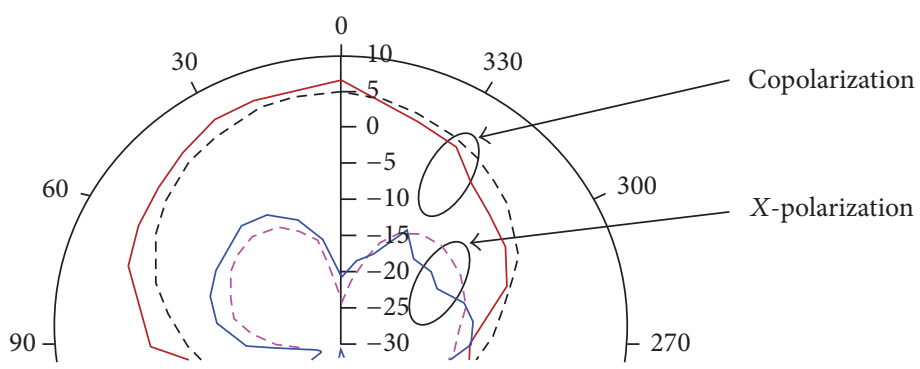

(g) $H$-plane, $2.4 \mathrm{GHz}$

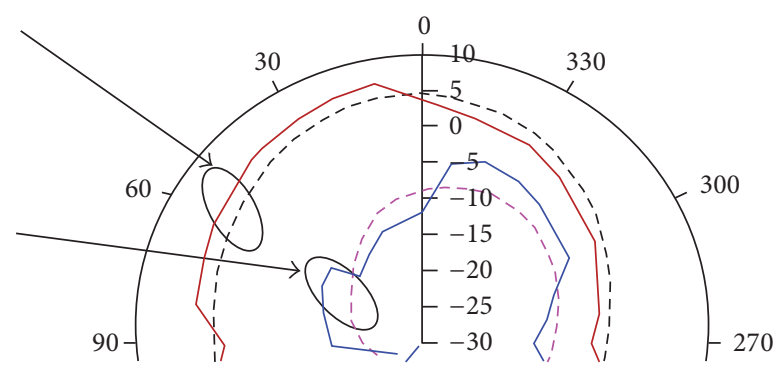

(b) E-plane, $1.57 \mathrm{GHz}$

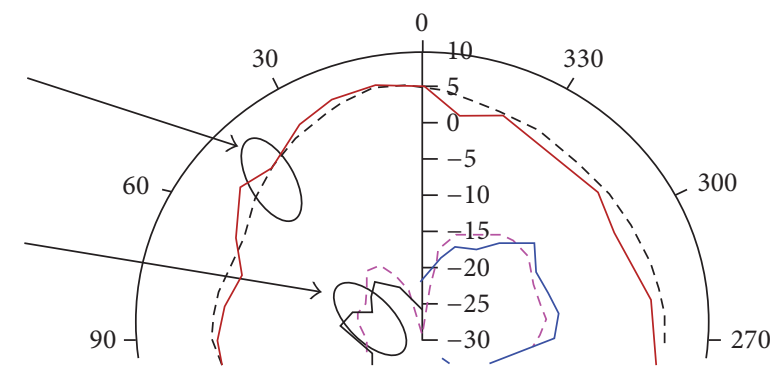

(d) E-plane, $2.5 \mathrm{GHz}$

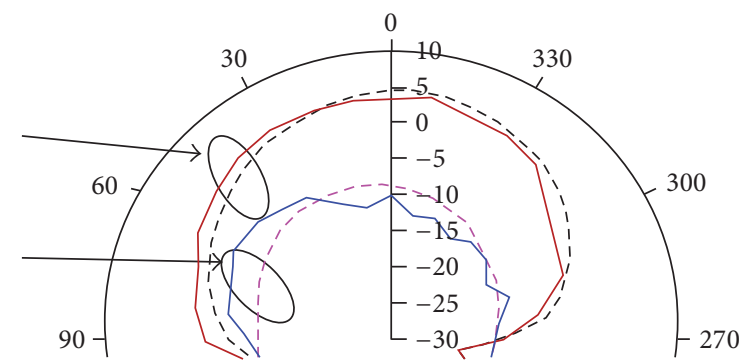

(f) $H$-plane, $1.57 \mathrm{GHz}$

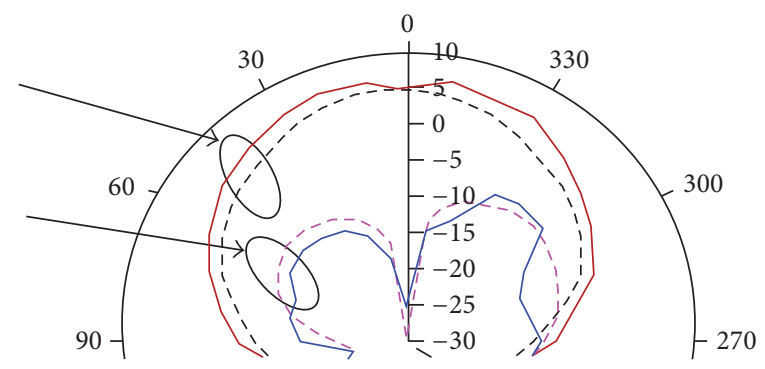

(h) $H$-plane, $2.5 \mathrm{GHz}$

FIGURE 14: Simulated and measured copolarization and cross-polarization radiation patterns: black long dash, simulated copolarization; brown solid line, measured copolarization; pink short dash, simulated cross-polarization; blue solid line, measured cross-polarization.

TABLE 3: Diversity performance of the proposed structure.

\begin{tabular}{lcccrr}
\hline$f(\mathrm{GHz})$ & $\mathrm{MEG}_{1}(\mathrm{dBi})$ & $\mathrm{MEG}_{2}(\mathrm{dBi})$ & $\mid$ MEG1/MEG2| $(\mathrm{dB})$ & $\mathrm{ECC}$ & \\
\hline 1.47 & -3.12 & -3.14 & 0.02 & 0.05 & \\
1.57 & -3.75 & -3.76 & 0.01 & 0.06 & 9.97 \\
2.4 & -3.32 & -3.30 & 0.02 & 0.02 & 9.95 \\
2.5 & -3.52 & -3.53 & 0.01 & 0.02 & 9.98 \\
\hline
\end{tabular}




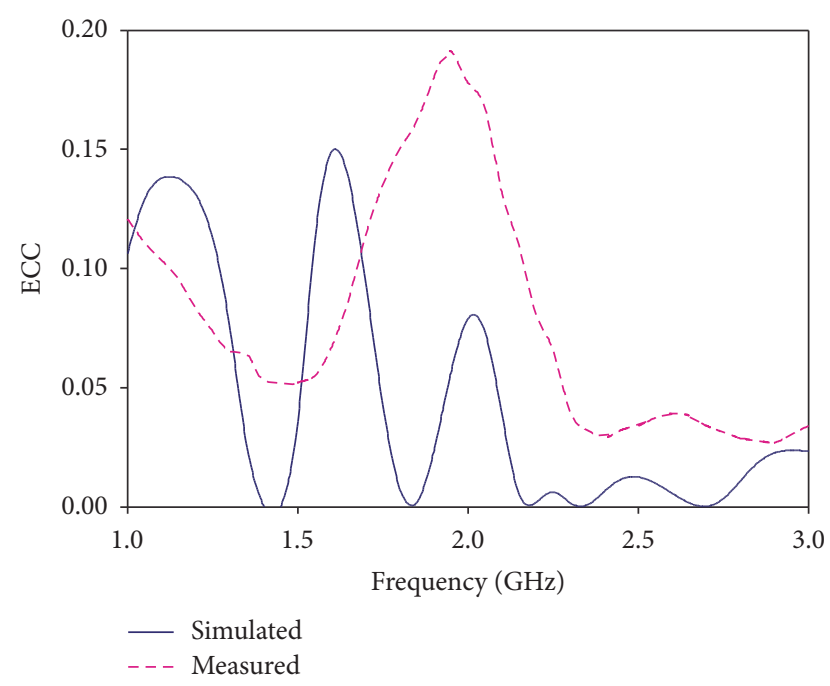

FIGURE 15: Simulated and measured envelope correlation coefficient for first configuration.

\section{Acknowledgments}

The authors would like to thank the Ministry of Education (MOE) and UTM GUP (Vot 4J211, 05H62, 03G33, and 11H59) for sponsoring this work.

\section{References}

[1] M. Mustaqim, K. Khan, and M. Usman, "LTE-advanced: requirements and technical challenges for $4 \mathrm{G}$ cellular network," Journal of Emerging Trends in Computing and Information Sciences, vol. 3, no. 5, pp. 665-671, 2012.

[2] M. K. Meshram, R. K. Animeh, A. T. Pimpale, and N. K. Nikolova, "A novel quad-band diversity antenna for LTE and Wi-Fi applications with high isolation," IEEE Transactions on Antennas and Propagation, vol. 60, no. 9, pp. 4360-4371, 2012.

[3] Q. Rao and D. Wang, "A compact dual-port diversity antenna for long-term evolution handheld devices," IEEE Transactions on Vehicular Technology, vol. 59, no. 3, pp. 1319-1329, 2010.

[4] H. S. Singh, M. Agarwal, G. K. Pandey, and M. K. Meshram, "A quad-band compact diversity antenna for GPS L1/Wi-Fi/ LTE2500/WiMAX/ HIPERLAN1 applications," IEEE Antennas and Wireless Propagation Letters, vol. 13, pp. 249-252, 2014.

[5] S. Manafi, S. Nikmehr, and M. Bemani, "Planar reconfigurable multifunctional antenna for WLAN/wimax/UWB/pcsdcs/ UMTS applications," Progress in Electromagnetics Research C, vol. 26, pp. 123-137, 2012.

[6] A. Petosa, Dielectric Resonator Antenna Handbook, Artech House, 2007.

[7] I. Messaoudene, T. A. Denidni, and A. Benghalia, "CDR antenna with dual-band 1.9/2.7 GHz for MIMO-LTE terminals," Microwave and Optical Technology Letters, vol. 57, no. 10, pp. 2388-2391, 2015.

[8] L. Huitema, M. Koubeissi, M. Mouhamadou, E. Arnaud, C. Decroze, and T. Monediere, "Compact and multiband dielectric resonator antenna with pattern diversity for multistandard mobile handheld devices," IEEE Transactions on Antennas and Propagation, vol. 59, no. 11, pp. 4201-4208, 2011.
[9] Y. X. Sun and K. W. Leung, "Dual-band and wideband dual-polarized cylindrical dielectric resonator antennas," IEEE Antennas and Wireless Propagation Letters, vol. 12, pp. 384-387, 2013.

[10] N. M. Nor and M. H. Jamaluddin, "A dual band mimo dielectric resonator antenna for wlan application," Jurnal Teknologi, vol. 77, no. 10, pp. 1-4, 2015.

[11] M. Agarwal, R. Singh, and M. K. Meshram, "Linearly polarised planar inverted F-antenna for global positioning system and worldwide interoperability for microwave access applications," IET Microwaves, Antennas and Propagation, vol. 7, no. 12, pp. 991-998, 2013.

[12] G. Park, M. Kim, T. Yang, J. Byun, and A. S. Kim, “The compact quad-band mobile handset antenna for the LTE700 MIMO application," in Proceedings of the 2009 IEEE International Symposium on Antennas and Propagation and USNC/URSI National Radio Science Meeting (APSURSI '09), pp. 1-4, Charleston, SC, USA, June 2009.

[13] S. Park, J. Lee, and A. S. Kim, "Dual-port LCP multi-band antenna for WiBro/mWiMax MIMO, Bluetooth and GPS applications in mobile phone," in Proceedings of the Antennas and Propagation Society International Symposium (APSURSI '09), p. 14, Charleston, SC, USA, June 2009.

[14] D. Wang and Q. Rao, "Integrated design of multiple antennas for WiFi/Bluetooth/GPS mobile communication," in Proceedings of the Progress in Electromagnetics Research Symposium (PIERS '10), pp. 755-758, Cambridge, Mass, USA, July 2010.

[15] R. Głogowski and C. Peixeiro, "Multiple printed antennas for integration into small multistandard handsets," IEEE Antennas and Wireless Propagation Letters, vol. 7, pp. 632-635, 2008.

[16] X. S. Fang and K. W. Leung, "Designs of single-, dual-, wideband rectangular dielectric resonator antennas," IEEE Transactions on Antennas and Propagation, vol. 59, no. 6, pp. 2409-2414, 2011.

[17] HFSS Ansoft (Part of ANSYS Inc.), http://www.ansys.com/Products/Electronics/ANSYS-HFSS.

[18] L. Z. Thamae and Z. Wu, "Broadband bowtie dielectric resonator antenna," IEEE Transactions on Antennas and Propagation, vol. 58, no. 11, pp. 3707-3710, 2010.

[19] Y.-S. Shin and S.-O. Park, "Spatial diversity antenna for WLAN application," Microwave and Optical Technology Letters, vol. 49, no. 6, pp. 1290-1294, 2007.

[20] K. K. So and K. W. Leung, "Bandwidth enhancement and frequency tuning of the dielectric resonator antenna using a parasitic slot in the ground plane," IEEE Transactions on Antennas and Propagation, vol. 53, no. 12, pp. 4169-4172, 2005.

[21] Infineon application notes, http://www.alldatasheet.com/datasheetpdf/pdf/78978/INFINEON/BAR64-02V.html.

[22] R. G. Vaughan and J. B. Andersen, "Antenna diversity in mobile communications," IEEE Transactions on Vehicular Technology, vol. 36, no. 4, pp. 149-172, 1987. 


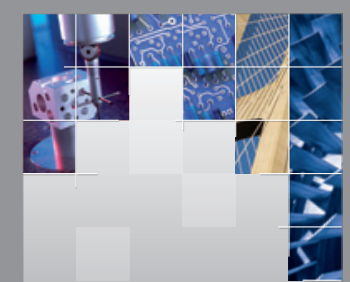

\section{Enfincering}
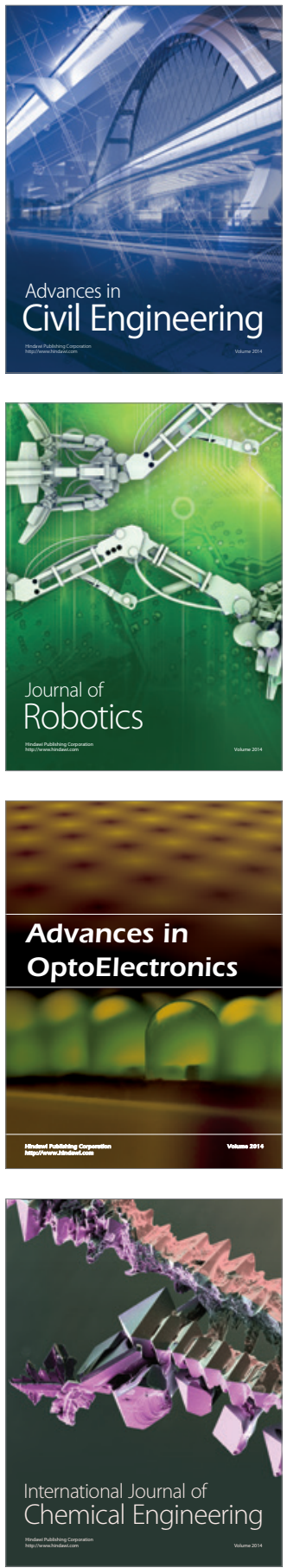

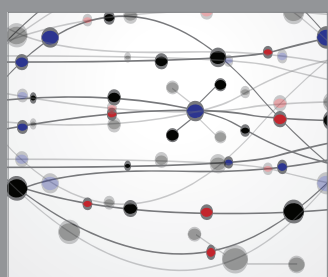

The Scientific World Journal

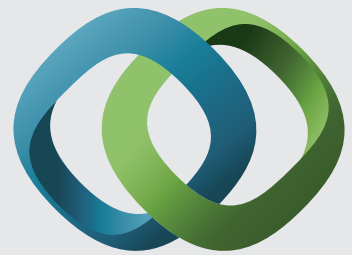

\section{Hindawi}

Submit your manuscripts at

http://www.hindawi.com
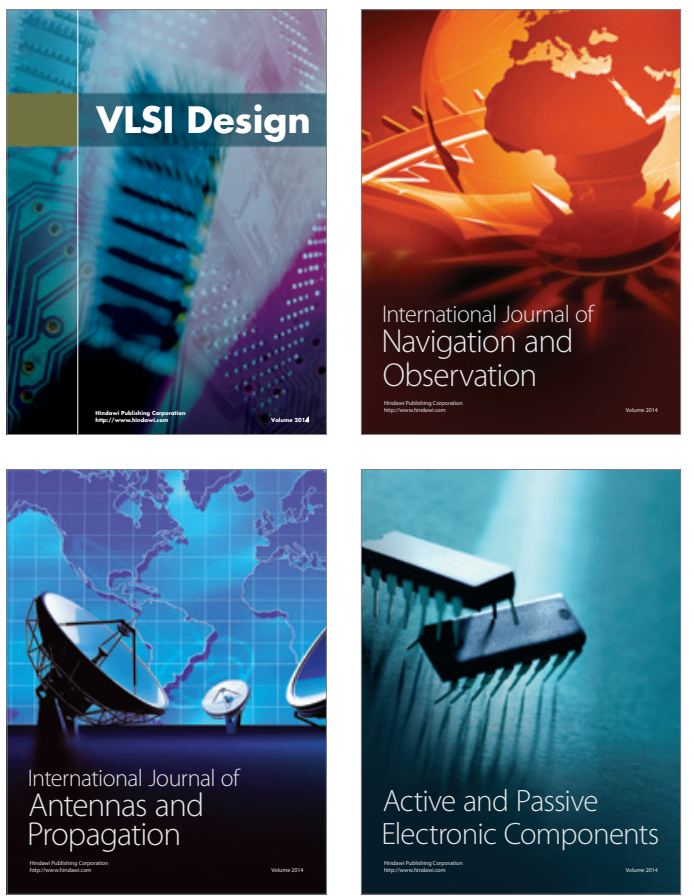
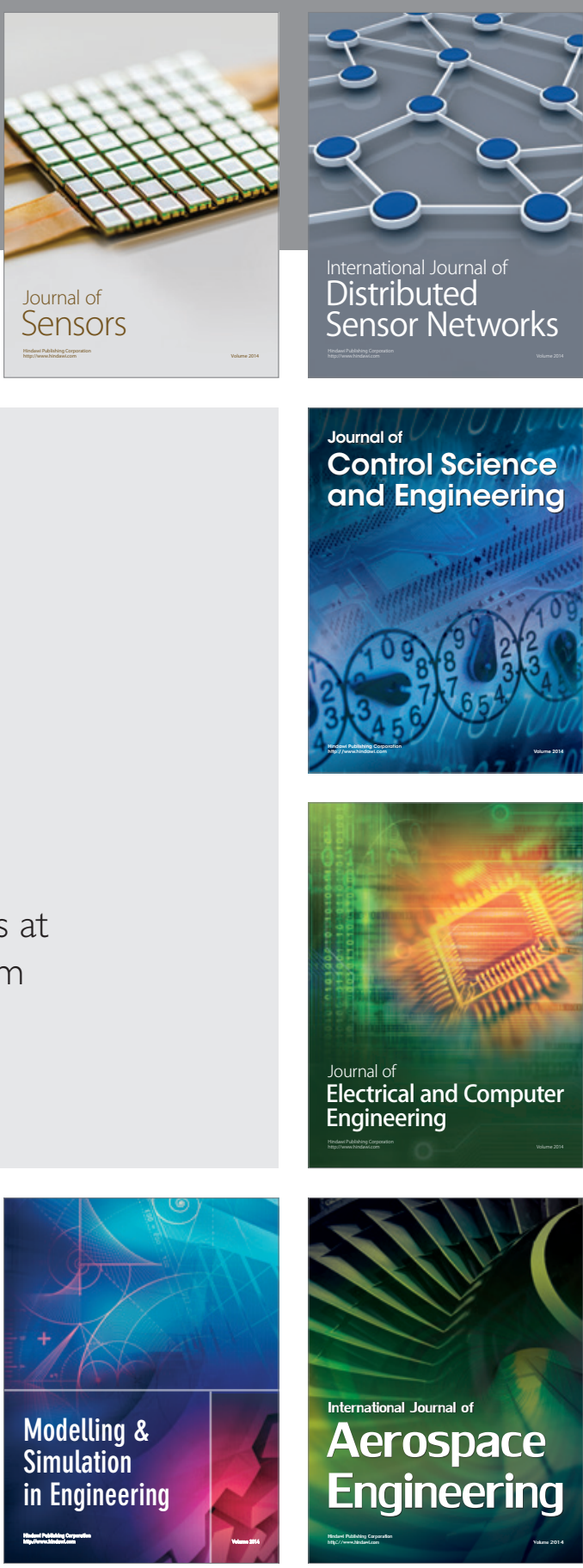

International Journal of

Distributed

Sensor Networks

Journal of

Control Science

and Engineering
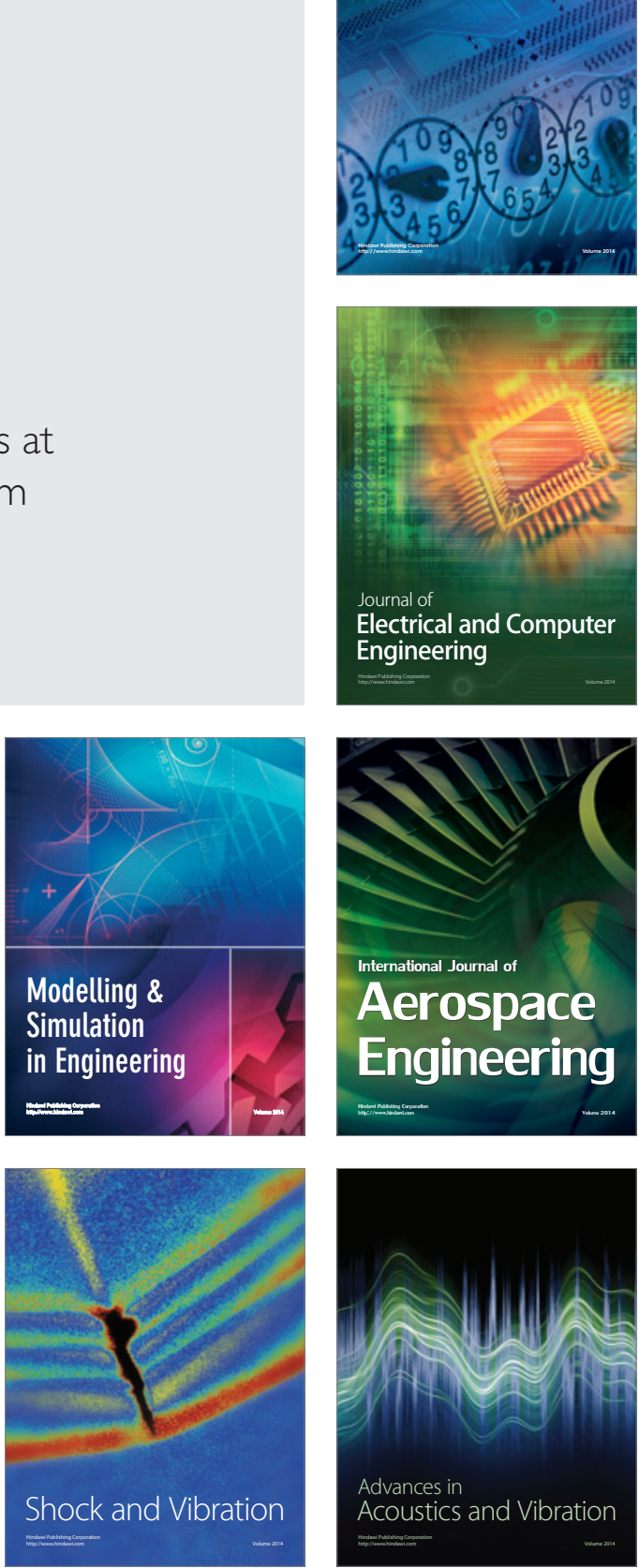